\title{
Possible Toxicological Effect of Pesticides, Fipronil On Earthworm (Eudrilus eugeniae)
}

\author{
Urvi Patel $^{1^{*}}$, Rakesh Prajapati ${ }^{2}$ \\ ${ }^{I}$ Student, Department of Life Sciences, Hemchandrachary North Gujarat University, Patan, India \\ ${ }^{2}$ Assistant Professor, Department of Biology, M. N. College, Visnagar, India \\ *Corresponding author: urvipatel36602@gmail.com
}

\begin{abstract}
Pollution is the preface of infect into an environment, may also defined as an unwanted modify in the physical, chemical and biological characteristics of air, water and soil which influence human life, lives of other useful alive plants and animals, industrial progress, alive conditions and florescent property Water is the most necessary \& major necessaries of life. One can rarely survive without water also for a few days. At that $2 / 3$ of the world's float up region is enclosed by water but yet we are blank. An incubation study was conducted to know the toxicity level of Fipronil in soil fauna by using earthworm species Eudrilus eugeniae as a biomarker. The earthworm were incubated in the spiked soil, with concentration of $17 \mathrm{ml}, 18 \mathrm{ml}, 19 \mathrm{ml}, 20 \mathrm{ml}$ for a period of $24 \mathrm{hours}$ and 48 hours. From the study, 50\% mortality was observed in $17 \mathrm{ml}$. The $\mathrm{LC}_{50}$ concentration were calculated from that it was clear that Fipronil is toxic to earthworm.
\end{abstract}

Keywords: Bioassay test, Eudrilus eugeniae, Fipronil, Non target animal.

\section{Introduction}

Soil can also be clear as a natural body which is creation at the border between lithosphere and biosphere by inter chains of the entire ingredient involve in soil arrangement considering both alive and dead. So soil contains not only metal but organic (human) and Organo metal (complex or chilate) combination. Ecological pollution is organism the burning dare of existing living being on the earth. Pollution is the preface of infect into an environment, may also defined as an unwanted modify in the physical, chemical and biological characteristics of air, water and soil which influence human life, lives of other useful alive plants and animals, industrial progress, alive conditions and florescent property. Most of the surface flows of rivers in our nation take place during the heavy rain season of 4 to 5 months and mainly as flood flows. Water toxic waste become when unnecessary equipment go in to water, modification the verity of water (Alrumman et al., 2016) and damaging to atmosphere and human health (Briggs, 2003). Water is a significant natural source used for consumption and other developmental aim in our life (Bidi et al., 2016). An earthworm is a tube- shaped, segmented worm found in the phylum is Annelida. Earthworms are commonly found in living in soil, feeding on live and death organic matter. An earthworm's digestive system runs through the length of its body. It conducts respiration through its skin. I have a double transport system composed of coelomic fluid that moves within the fluid filled coelom and a simple, closed blood circulatory system. It has a central and a peripheral nervous system.

They change soil structure, fertility, develop plant growth and are significant in sustaining productivity (Bucker field, 1998). Earthworm is one which has always interested to mankind; it is nature's own farmer, aerator, crusher, composter, and humidity builder of the top soil and above all is soil's intimate friend and benefactor (Watanabe, 1975 and Lal, 1988). The more Chemical cluster of germicides that are generally useful Organophosphate, Carbamate, Chlorinated Hydrocarbons, Pyrethroids and Nicotinoids. Dangerous spraying and shocking management of the chemical pesticides may due to very danger of the health hazard. Fipronil, an $\mathrm{N}$ phenylpyrazole, was introduced into the United States in 1996 for use in animal health, inside pest manage, and commercial turf and crop defense. The use of chemical pesticides has taken place seriously significant to assure both quality and productivity of agricultural products (Oerke and Dehne., 2004; Hayasaka et al., 2012) and to manage household pests such as termites, fire ants, and mosquitoes (Elliott and Barnes, 1963; Drees, 2014). Pesticide coverage is linked with diverse illness along cancer, hormone disruption, asthma, allergies, and hypersensitivity (Van Maele-Fabry et al., 2010). A stroke of proof as well breathe for the opposite effect of pesticide coverage major to birth demerit, abridged birth heaviness, fetal death, etc. (Baldi et al., 2010; Meenakshi et al., 2012; Wickerham et al., 2012).

Pesticides have the possible to due to refuse in farmland bird populations by deplete their food stuff provide. This may occur due to organisms in use as food stuff by farmland birds are either invertebrate vermin or harmful grass that are intentionally notice by pesticides, or because non target organisms that are even diet items for birds are eject occasionally by pesticide application. As these treating do not absorb through poisoning of birds because the toxicity of the energetic ingredients in pesticides or their metabolites, they have be termed not direct impact (Newton, 1995). The analysis that not direct impact of pesticides were drivers of the deny in Grey Partridge populations in Britain was only feasible due to 
the demography and behavioral biology of the Grey Partridge had been the topic of a compact and continuing study by the Game sanitation faith and others (Potts, 1986; Aebischer \& Ewald, 2004).

When croplands are treating, some effects of pesticides take place on non-target terrestrial and marine ecosystem, as well as on adjacent agro ecosystems (Surendra, 2010). As pesticides humiliate, they may filter into soil and water, or they may be desolate or unstable arrive adjacent, or far, areas (Kreisler and Heiss, 2008). Women who consume lots of fish from impure waters have been exposed to have children with high charge of mental, evolution, and behavioral disarray (Ram, 2002). The impact on fish is fall mostly duration the reproductive cycle (Burdick et al., 1967). Some farmers account under estimated the toxicity of the pesticides and thought that throw of report pesticides in runny water was their protected removal. The unless selection to removal of the conclude pesticides was to put in the ground them in fields (Khooharo, 2008).

\section{Fipronil}

Fipronil[5-amino-3-cyano-1-(2,6-dichloro-4-

trifluoromethylphenyl)-4 fluoromethyl sulfonyl pyrazole] is another establishment phenylpyrazole insecticide used extensively as a farming and veterinary pesticide (US Environmental Protection Agency, 1996; Hovda and Hooser, 2002; Tingle et al., 2003). Fipronil was first registered for animal physical condition in the USA in 1996, consisting of Front line perfusion, containing $0.29 \% \mathrm{w} / \mathrm{w}$ fipronil (Technical Information Sheet, 1997), and Front line Top mark, containing 9.7\% fipronil w/w (Technical Information Sheet, 1997). Fipronil containing products have established an impressive treatment to control parasites (Hutchinson et al., 1998; Ritzhaupt et al., 2000; Cadiergues et al., 2001; Jacobs et al., 2001; Mehlhorn et al., 2001; Moyses and Gfeller, 2001; Medleau et al., 2002; Medleau et al., 2003), ticks (Young et al., 2003), biting lice (Pollmeier et al., 2002; Pollmeier et al., 2004), trombiculid mites (Nuttall et al., 1998) and other mites (Curtis, 1996; Bordeau and Hubert, 2000; Curtis, 2004) in dogs and cats. Veterinary pesticides containing fipronil have the subsequent label claims perfusion: up to 12 weeks for parasites on dogs and 8 weeks for parasites on cats; parasites Allergy Dermatitis (FAD) apply monthly; paralysis ticks relate every 3 weeks, brown dog tick up to 4 weeks. Dog mark on monthly for parasites, FAD and brown dog tick;2 weeks for paralysis tick.

The moiety life of fipronil is $122-128$ days in aerobic soils. Under aerobic situation, obviously occurring soil organisms collapse fipronil to form fipronil sulfone. Fipronil can also be hydrolyzed to form fipronil-amide (Bobe et al., 1998).

Fipronil has display neurotoxicity in the severe and sub chronic rat neurotoxicity studies, as well as in the rat chronic/on cogenicity and chronic dog studies. Behavioral changes and loss plenary brain weights were look only at orbit where there was motherly toxicity (decreased body weight, body-weight gain and food consumption) (USEPA, 1998).

\section{Proposed Study}

As per statistic, production and productivity have increased. However, the high chemical usage of pesticides to bring about these spectacular increases in food production is not without its problems. A visible parallel correlation between higher productivity, high chemical input use and environment degradation effects is evident in south Gujarat were commercial agriculture is widespread. Crop like rice, maize, jowar, cotton, mangoes, cheeku, bajra, wheat, tobacco, ground nuts, tur, gram all types of vegetables are grown in north Gujarat to get more production farmers use various types of pesticides. Fipronil is most commonly used pesticides which are used as insecticides. Therefore, present work is aimed to evaluate the toxicity effects of widely used pesticides, fipronil an economically important animal Eudrilus eugeniae. An earthworm is a tube- shaped, segmented worm found in the phylum is Annelida. Earthworms are commonly found in living in soil, feeding on live and death organic matter. An earthworm's digestive system runs through the length of its body. It conducts respiration through its skin. I have a double transport system composed of coelomic fluid that moves within the fluid filled coelom and a simple, closed blood circulatory system. It has a central and a peripheral nervous system.

The earthworms are a group of invertebrates belonging to the phylum Annelida and Class Oligochaeta and represented by more than 1000 species. Earthworm is a face organism and it is present in moist and dark places in mud. Earthworms are of great economic value to mankind because they improve the soil quality by their action. Earthworms ingest organic material and facilitate the redistribution of crop residues and organic matter throughout the soil profile. In the Indian subcontinent earthworms are represented by 509 species in 67 genera under 10 families. They are segmented worms, bilaterally symmetrical, with an external gland (clitellum) for producing the egg case (cocoon), a sensory lobe in front of the mouth (prostomium), and an anus at the end of the animal body, with a small number of bristles (setae) on each segment.

Earthworms are a group of soil macro fauna well known for their remarkable contribution in organic matter recycling. The worms have long been related with creative soils. They change soil structure, fertility, develop plant growth and are significant in sustaining productivity (Bucker field, 1998). Earthworm is one which has always interested to mankind; it is nature's own farmer, aerator, crusher, composter, and humidity builder of the top soil and above all is soil's intimate friend and benefactor (Watanabe, 1975 and Lal, 1988). Earthworms play a vital role in soil fertility through the influence on water regime, aggregation, litter involment, soil organic dynamics and microbial activity (Briones et al., 1998).

Assessment of fipronil toxicity was designed to carry out with TLm (Median Tolerance Limit) test for $96 \mathrm{hrs}$. The median tolerance limit (TLm) is the attention which is used to articulate the result of toxicity test (bioassay) to point to the stamina of $50 \%$ survival of the test animals throughout certain 
experimental epoch. At the same time, behavioral modify of the earthworm with the fipronil were undertaken.

\section{Method and Material}

\section{A. Experimental Animal}

Healthy and active Earthworm Eudrilus eugeniae having size of $6.5 \pm 1.5 \mathrm{~cm}$ were procured from the Ganpat University, Kherva village of Mahesana district, India. Before investigation Earthworm maintained at least for 10 days in laboratory floor containing dough of fertilizer. All dough of fertilizer were kept in the laboratory in cool place and covered with bag of jute and also use iron net to prevent the escape of animals and the foreign particles falling in. Dead specimens were removed immediately. Dough of fertilizer renewed every week. Chose different concentration like $17 \mathrm{ml}, 18 \mathrm{ml}, 19 \mathrm{ml}$, and $20 \mathrm{ml}$ this concentration of solutions were prepared from the stock solution, and these are used for the bioassay test. The soil was mixed carefully with a glass rod.

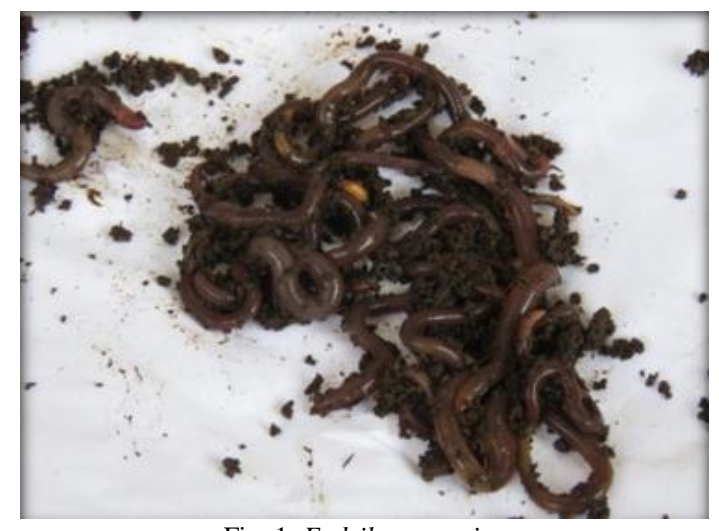

Fig. 1. Eudrilus eugeniae

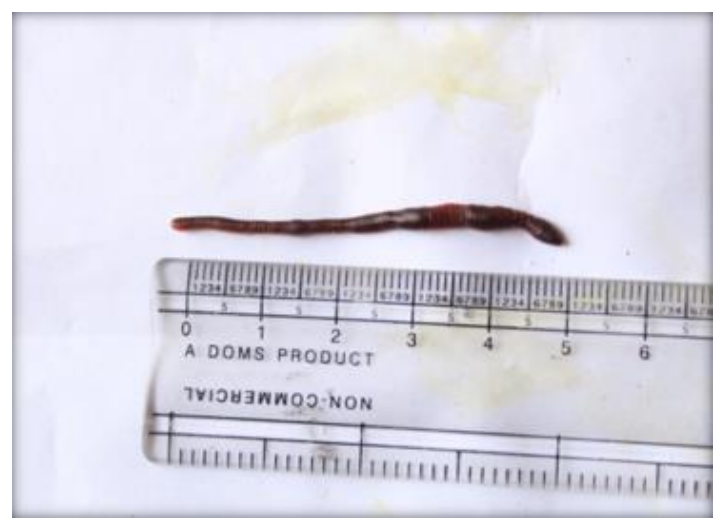

Fig. 2. Eudrilus eugeniae measuring

\section{B. Pesticides}

The technical formulation of Fipronil (Lethal, SC 5\%) a type of organophosphorus pesticide was selected for the study. The pesticide was purchased from the local pesticide supplier, Visnagar, Gujarat, India and used to check its impact on Earthworm.

\section{Bioassay Test}

The median tolerance limit (TLm-96 hrs) of Fipronil for the was Eudrilus eugeniae determined in the laboratory through static renewal bioassay test using standard method as described in APHA, (1995).

For the purpose of bioassay test, earthworms from the vermicompost $(100 \mathrm{gm})$ were used. For determining the $\mathrm{LC}_{50}$ selected 20 worms having similar size were inserted into each earthen port containing pesticide in different concentrations (ppm). First, the animals were exposed to different concentrations for range finding test where the lowest concentration at which $0 \%$ and the highest concentration for $50 \%$ mortality occurred.

No feed was given before $24 \mathrm{hrs}$ and during the bioassay test. Test medium was renewed for every $24 \mathrm{hrs}$ with their respective test concentration of the toxicant without aeration. Dead specimens were removed immediately as and when found mortality rate was recorded at the end of 24, 48, 72 and 96hrs. The median tolerance limit (TLm $96 \mathrm{hrs)}$ ) was obtained by plotting graph with concentration series against the mortality rate for $96 \mathrm{hrs}$. All the exposures were repeated at least three times to maintain the consistency in the results.

\section{Result and Discussion}

\section{A. Bio-assay Test}

Depicts the mortality and survival of Eudrilus eugeniae exposed to different concentration of Fipronil. Concentration at which minimum mortality (50\%) Eudrilus eugeniae recorded was $17 \mathrm{ml}$ and maximum concentration where $70 \%$ mortality noted was $20 \mathrm{ml}$. The exposure of Eudrilus eugeniae Fipronil treatment was most critical at $24 \mathrm{hrs}$.

\section{B. Behavioral Responses}

After application pesticides in soil instantly, animals were trying to jump out side of the earthen port. When the earthworm was exposed to various concentration of fipronil, they move immediately to the surface of the earthen port. The movement of earthworm was observed to be disrupted from $24 \mathrm{hrs}$ of exposure. Irregular movement followed by imbalanced slide activity was observed. The sliding behavior was sudden, rapid non directed spurt of surface movement. The earthworm progressively showed signs of higher concentration $(17,18,19$, $20 \mathrm{ml}$ ) showed that animal lost their equilibrium and response to external stimuli such as touch by drowning to the soil trap and correspondingly died. Eudrilus eugeniae body color changes dark red to light red. 


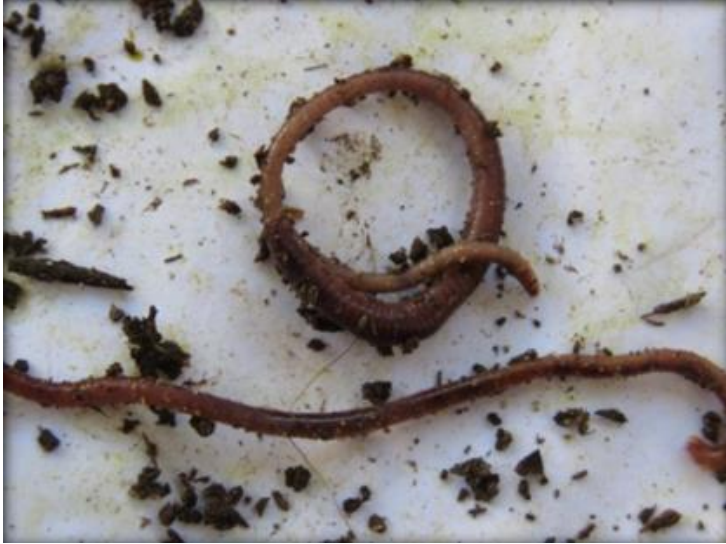

Fig. 3. Change of color

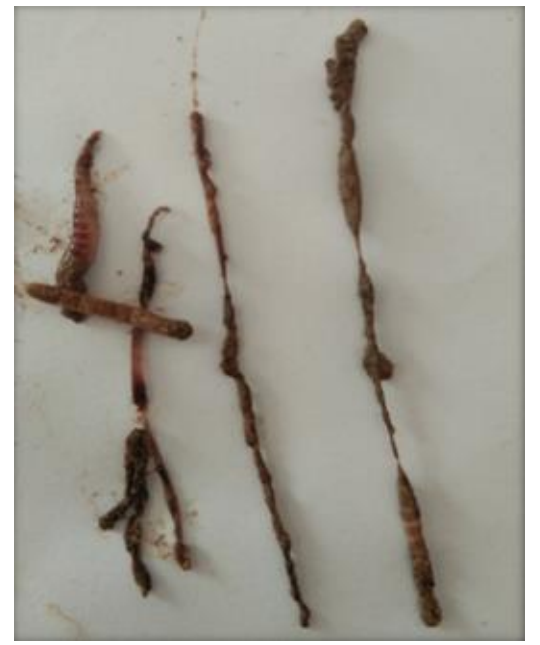

Fig. 4. Putrefy E.eugeniae

Table 1

Mortality of Eudrilus eugeniae exposed to Fipronil

\begin{tabular}{|c|l|l|l|c|c|}
\hline $\begin{array}{c}\text { S. } \\
\text { No. }\end{array}$ & $\begin{array}{c}\text { Concentration of } \\
\text { Fipronil in (ml) }\end{array}$ & $\begin{array}{c}\text { No. of } \\
\text { Earthworm } \\
\text { Exposed }\end{array}$ & \multicolumn{2}{|c|}{$\begin{array}{c}\text { Mortality } \\
\text { in } \\
\text { Numbers }\end{array}$} & $\begin{array}{c}\text { Mortality } \\
\text { in \% }\end{array}$ \\
\cline { 3 - 6 } & & & $\begin{array}{c}\mathbf{2 4} \\
\text { hrs }\end{array}$ & $\begin{array}{c}\mathbf{4 8} \\
\text { hrs }\end{array}$ & \\
\hline 1. & 17 & 20 & 10 & 0 & 50 \\
\hline 2. & 18 & 20 & 13 & 0 & 65 \\
\hline 3. & 19 & 20 & 13 & 1 & 70 \\
\hline 4. & 20 & 20 & 15 & 0 & 75 \\
\hline
\end{tabular}

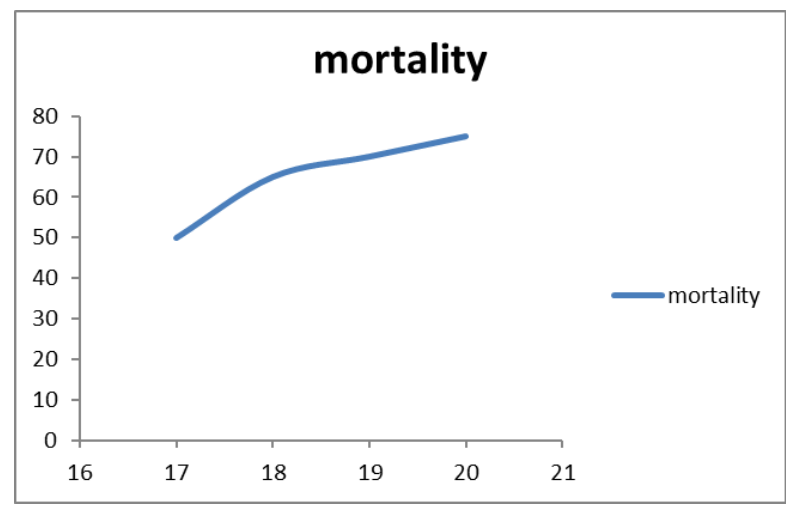

Fig. 5. Sigmoid curve between percentage mortality of E.eugeniae and concentration of Fipronil
Evaluated as toxicity grade of urea was categorized as "very toxic" to E. fetida. With consistent area of contact exposure of urea to the earthworm in different concentrations showed various toxic effects in filter paper substrate $28 \mu \mathrm{g} / \mathrm{cm}^{2}$ by an average calculation. Thus, the comparative medium on the Petri plate bed. A geometric concentration series of test solution (5, $10,20,40$, and $80 \mathrm{mg} / 5 \mathrm{ml}$ ) was prepared and tested, in which mortality of earthworms was observed in 20,40 , and $80 \mathrm{mg}$ concentrations after 18,12 , and $6 \mathrm{hr}$, respectively. Only the 5 $\mathrm{mg} / 5 \mathrm{ml}$ concentration was non-toxic to earthworm for $48 \mathrm{hr}$. The lethal concentration for $48 \mathrm{hr}$ to E. fetida was $10 \mathrm{mg} / 5 \mathrm{ml}$ concentration. The earthworm was not able to move around after $40 \mathrm{hr}$, neural retention and defoliation starts, and the body parts separate leading to the death. The lethal effect of the regularly used chemical fertilizer urea is killing the friend of farmer in a drastic way. In this preliminary screening experiment, the chemicals are shocked or absorbed into the earthworm body mainly through the outer dermal layer of skin when it is moving around the filter paper (Smetak et al., 2007, Estevez et al., 1996, Potter et al., 1985). The study found the organophosphorus pesticide chlorpyrifos is toxic to be earthworm species Eudrilus eugeniae at a concentration of 100 ppm, which showed 100 per cent mortality within 24 hours. Earthworm is one of the macro fauna indicator species. From the prohibit analysis high level of LC value can be seen from prohibit analysis so the study gives the information that the chlorpyrifos is toxic to earthworms at high concentrations levels from $100 \mathrm{ppm}$. L. rohita was silvery white in body in the control group throughout the experiment. The body colour changed from original silvery white to dark colour in pesticide treated fish. The fish maintained in freshwater behaved normal as body colour changed from original silvery white usual. But when the fish was exposed to pesticides monocrotophos and lambda cyhalothrin, erratic swimming, abnormal posture, disbalance, sluggishness, imbalance in posture, increase in surface activity, opercula movement, and gradual loss of equilibrium and spreading of excess of mucus all over the surface of the body were observed. A survey of LC50 values of different pesticides to the fish for different periods of exposure reveals the occurrence of a wide differences between duration of exposure and types of fishes (Macek and McAllister, 1970; Holden, 1972; Carter and Graves, 1973; Bakthavathasalam, 1980; Koundinya and Ramamurthi, 1980; Padmini, 1980; Rani et al., 1990; Dhanalakshmi, 1991; Sadhu, 1993; Pickering and Henderson, 1966; Santhakumar and Balaji, 2000; Mathivanan, 2004 and Ramasamy et al., 2007). Changes in body colour have been reported in Anabas testudineusafter exposure to monocrotophos (Santhakumar and Balaji, 2000), $C$. punctatusto organophosphorus (Sandhu, 1993) and Cyprinuscarpioto ammonia stress (Israeli-weinstein and Kimmel, 1998).

The behavioral changes are considered directly related to complex physiological responses and have often been used as a sensitive indicator of stress (Little and Finger, 1990). The 
change of body colour, behavioral changes such as irregular swimming movements, loss of equilibrium, restlessness and excess secretion of mucous suggest that $L$. rohita has undergone chemical stress when exposed to pesticide and the present study could be taken as an indicator of aquatic pollution. Result of $\mathrm{LC}_{50} 96 \mathrm{hr}$ for both toxins showed that it decreases with increasing toxin concentration and duration of exposure. It means that by increasing the duration, lower concentrations of the toxins were required to kill $50 \%$ of fish and $\mathrm{LC}_{50}$ values in the first 24 hours of the experiment were more than the end of the 96-hour $\mathrm{LC}_{50}$. Exposure time is one of the effective factors in OPs toxicity (Larkin \& Tjeerdema, 2000). When fish are exposed to a constant concentration of toxins, their tolerance diminishes over time and the toxin has more time to affect. In toxic environments, fish exhibited irregular, erratic and darting swimming movements and loss of equilibrium which is due to inhibition of acetyl cholinesterase (AChE) activity leading to accumulation of acetylcholine in cholinergic synapses causing hyper stimulation.

\section{Conclusion}

After this experiment it was found that when pesticides mixing in soil. Within $24 \mathrm{hrs}$, the effects are most pronounced on the earthworm. After $24 \mathrm{hrs}$, the earthworms become stable. The pesticides concentration in the soil decreases so it does not have an effect on the earthworm after $24 \mathrm{hrs}-96 \mathrm{hrs}$.

Finding of the work carried out during the experiment Eudrilus eugeniae different concentration of Fipronil which is used in agriculture to control the pests and indicated that the pesticide was lower toxic. Due to high humidity and low temperature, the effect of pesticides on the earthworm is less effect and low humidity and high temperature, the effect of pesticides on earthworm is more effect. Although the pesticide is more effective, the more effect on the earthworm. From the study, $50 \%$ mortality was observed in $17 \mathrm{ml}$. The $\mathrm{LC}_{50}$ concentration were calculated from that it was clear that Fipronil is toxic to earthworm.

\section{Acknowledgment}

I am very thankful to my guide Dr. Rakesh Prajapati, Assistant Professor, Department of Biology, M. N. College, Visnagar for given me an excellent and perfect guidance at any movement during this work. I also indebted for his suggestion and constructive comments which enable me to complete this work in time. I own my success to him.

\section{References}

[1] Aebischer, N. J. \& Ewald, J. A., "Managing the UK grey partridge Perdixperdixrecovery: population change, reproduction, habitat and shooting". Ibis 146 (Supplement 2), 181-191, 2004.

[2] Alrumman, S. A., Elkott, A. F. and Kehsk, M. A, "Water pollution: Source and treatment. American journal of Environmental Engineering". 6(3):8898, 2016.

[3] Bakthavathsalam, R., "Toxicity and physiological impact of three selected pesticides of an air-breathing fish, Anabas testudineus(Bloch)". Ph.D. Thesis, Annamalai University, Tamil Nadu, India, 1980.
[4] Baldi, I., Gruber, A., Rondeau, V., Lebailly, P., Brochard, P., Fabrigoule, C., "Neurobehavioral effects of long-term exposure to pesticides: results from the 4-year followup of the PHYTONER study". Occup. Environ. Med. 68 (2), 108-115, 2010.

[5] Bibi, S., Khan, R. L., and Nazir R., "Heavy metals in drinking water of LakkiMarwat District, KPK, Pakistan”. World applied sciences journal. 34(1):15-19, 2016

[6] Bobe, A.; Meallier, P.; Cooper, J. F., Coste, C. M., "Kinetics and Mechanisms of Abiotic Degradation of Fipronil (Hydrolysis and Photolysis)". J. Agric. Food Chem., 46, 2834-2839, 1998.

[7] Bordeau, W., Hubert, B., "Treatment of 36 cases of canine Sarcoptesusing a $0.25 \%$ fipronil solution". Veterinary Dermatology 11, 27, 2000.

[8] Briggs, D., "Environmental pollution and the global burden of disease". British medical bulletin.68:1-24, 2003.

[9] Briones, M. J. I., Bol, R. and Sleep, B. "Isotopic ecology of earthworms under grassland and arable cropping system". $6^{\text {th }}$ International symp. Earthworm Ecol, vigo, Spain, pp, 1998.

[10] Buckerfield, J. C., "Earthworms are indicators of sustainable production". 6th international symp. Earthworm Ecol. Vigo, spain, 95, 1998.

[11] Cadiergues, M. C., Caubet, C., Franc, M., "Comparison of the activity of selamectin, imidacloprid and fipronil for the treatment of dogs infested experimentally with Ctenocephalidescanis and Ctenocephalidesfelisfelis," Veterinary Record, 149, 704-706, 2001.

[12] Carter, F. L. and Graves, J. B. "Measuring effects of insecticides on aquatic animals". Lousiana Artic. 16-14, 1973.

[13] Curtis, C. F., "Use of 0.25 per cent fipronil spray to treat sarcoptic manage in a litter of five-week-old puppies". Veterinary Record 139, 43-44, 1996.

[14] Curtis, C. F., "Current trends in the treatment of Sarcoptes, Cheyletiella and Otodectes mite infestations in dogs and cats". Veterinary Dermatology 15, 108-114, 2004.

[15] Dhanalakshmi, S., "Synergistic toxicity and effects of dimecroncuman on oxygen consumption and haematological parameters of freshwater teleost, Sarotherodonmossambicus(Peters)". M.Phil. Thesis, Bharathiar University, Coimbatore, Tamil Nadu, India, 1991.

[16] Drees, B. M., How to Select, "Apply, and Develop Insecticides for Imported Fire Ant Control". Texas A\&M AgriLife Extension Service. 8 p, 2014.

[17] Elliott, R., Barnes, J. M. "Organophosphorus Insecticides for the Control of Mosquitos in Nigeria". Trials with Fenthion and Malathion Conducted by the WHO Insecticide Testing Unit in 1960-61. Bull Org mondSante. ; 28:35-54, 1963.

[18] Estevez B., NEstevez B. A., Coderre D., "The effect on earthworm abundance and selected soil properties after 14 he es of solid cattle manure and NPK Mg fertilizer application". Can J Soil Sci; 76:351-5, 1996.

[19] Hayasaka, D., Korenaga, T., Suzuki, K., Saito, F., Sanchez, Bayo, F., Goka, K., "Cumulative ecological impacts of two successive annual treatments of imidacloprid and fipronil on aquatic communities of paddy mesocosms". Ecotoxicol Environ Saf.; 80:355-62, 2012.

[20] Holden, A. V., "The effects of pesticides on life in freshwater". Proc. Royal Soc., Lond. B., 180: 383-394, 1972.

[21] Hovda, L. R., Hooser, S. B., "Toxicology of newer pesticides for use in dogs and cats". Veterinary Clinics of North America: Small Animal Practice 32, 455-467. 2002.

[22] Hutchinson, M. J., Jacobs, D. E., Fox, M. T., Jeannin, P., Postal, J. M., "Evaluation of flea control strategies using fipronil on cats in a controlled simulated home environment". Veterinary Record 142, 356-357, 1998.

[23] Jacobs, D. E., Hutchinson, M. J., Ryan, W. G., "Control of flea populations in a simulated home environment model using lufenuron, imidacloprid or fipronil”. Medical and Veterinary Entomology 15, 73-77, 2001.

[24] Khooharo, A. A., "A study of public and private sector pesticide extension and marketing services for cotton crop". PhD thesis submitted to Sindh Agriculture University, Tando Jam, Sindh, Pakistan, 2008.

[25] Koundinya, P. R. and Ramamurthi, R., "Toxicity of sumithion and sevin to the freshwater fish, Sarotherodonmossambicus (Peters)," Curr. Sci., 49(22): 875-876, 1980.

[26] Kreisler, E. and Heiss, R., "Managing expired pesticides as hazardous waste across borders," The Eighth International Conference on Environmental Compliance and Enforcement, Washington, DC, 2008.

[27] Lal, R., "Effect of macrofauna on soil properties in tropical ecosystems". Agricul. Ecosys. Environ 24:101-116, 1988. 
[28] Larkin D. J., Tjeerdema R. S., "Fate and effects of diazinon. Reviews of environmental contamination and toxicology," 166:49-82. 13, 2000.

[29] Little, E. E. and Finger, S. E., "Swimming behaviour as an indicator of sublethal toxicity in fish". Environ. Toxicol. Chem, 9: 13-19, 1990.

[30] Macek, K. J. and McAllister, W. A., "Insecticide susceptibility of some common fish family representatives". Trans. Amer. Fish. Soc., 99(1): 2027, 1970.

[31] Mathivanan, R., "Effects of sublethal concentration of quinophos on selected respiratory and biochemical parameters in the fresh water fish Oreochromismossambicus". J. Ecotoxicol. Environ. Monit., 14 (1): 57-64, 2004.

[32] Medleau, L., Clekis, T., McArthur, T. R., Alva, R., Barrick, R. A., Jeannin, P., Irwin, J., "Evaluation of fipronil spot-on in the treatment of flea allergic dermatitis in dogs". Journal of Small Animal Practice 44, 71$75,2003$.

[33] Medleau, L., Hnilica, K. A., Lower, K., Alva, R., Clekis, T., Case, J., McArthur, T. R., Barrick, R. A., Jeannin, P., Irwin, J., "Effect of topical application of fipronil in cats with flea allergic dermatitis". Journal of the American Veterinary Medical Association 221, 254-257, 2002.

[34] Meenakshi, Sharon, P., Bhawana, M., Anita, S., V. K., G., "A short review on how pesticides affect human health". Int. J. Ayurvedic Herbal Medic. 5, 935-946, 2012.

[35] Mehlhorn, H., Hansen, O., Mencke, N., "Comparative study on the effects of three insecticides (fipronil, imidacloprid, selamectin) on developmental stages of the cat flea (Ctenocephalidesfelis Bouche 1835): a light and electron microscopic analysis of in vivo and in vitro experiments". Parasitology Research 87, 198-207, 2001.

[36] Moyses, E. W., Gfeller, F. J., "Topical application as a method for comparing the effectiveness of insecticides against cat flea (Siphonaptera: Pulicidae)". Journal of Medical Entomology 38, 193-196, 2001.

[37] Newton, I., "The contribution of some recent research on birds to ecological understanding". Journal of Animal Ecology, 64, 675-696, 1995.

[38] Nuttall, T. J., French, A. T., Cheetham, H. C., Proctor, F. J., "Treatment of Trombiculaautumnalis infestation in dogs and cats with a 0.25 per cent fipronil pump spray”. Journal of Small Animal Practice 39, 237-239, 1998.

[39] Oerke, E. C, Dehne, H. W. "'Safeguarding production losses in major crops and the role of crop protection". Crop Protection. 23(4):275-85. 2, 2004.

[40] Padmini, N.,"Toxicity and effects of pesticide sevin on blood free amino acids level of Tilapia mossambica (Peters)". M.Sc. Dissertation, University of Madras, Tamil Nadu, India, 1980

[41] Pickering, Q. H. and Henderson, C., "The acute toxicity of some pesticides to fish". Ohio. J. Sci., 66(5): 508 -513, 1966.

[42] Pollmeier, M., Pengo, G., Longo, M., Jeannin, P., "Effective treatment and control of biting lice, Felicolasubrostratus (Nitzsch in Burmeister, 1838), on cats using fipronil formulations". Veterinary Parasitology 121, 157-165, 2004

[43] Potter D. A., Bridges B. L., Gordon F. C., "Effect of N fertilization on earthworm and micro arthropod populations in Kentucky bluegrass". Turf Agron J; 77:361-12, 1985.

[44] Potts, G. R., “The Partridge Collins”, London, 1986.
[45] Ram, C. S., "Obsolete pesticides stockpiles in Nepal and its environmental impact". Forum for Protection of Public Interest (Pro Public), Kathmandu, Nepal, 2002.

[46] Ramasamy, P. K., Jeyaraj, R., Rajkumar David, A. J. and Ramaswamy, M., "Toxicity of an organophosphorus pesticide, quinalphos to the catfish, Mystusvittatus. J. Ecotoxicol”. Environ. Monit., 17 (4): 391-396, 2007.

[47] Rani, S., Shaik Dawood, A. and Ramasamy, M., "Toxicity of a carbamate fungicide, cuman to an edible, freshwater fish, Sarotherodonmossambicus(Peters)". J. Aquor., 3 (1): 29-36, 1990.

[48] Ritzhaupt, L. K., Rowan, T. G., Jones, R. L., "Evaluation of efficacy of selamectin, fipronil, and imidacloprid against Ctenocephalidesfelis in dogs". Journal of the American Veterinary Medical Association 217, $1669-1671,2000$.

[49] Sadhu, D. N., "Toxicity of an organophosphorous insecticide monocil to the air breathing fish, Channapunctuatus. J. Ecotoxicol. Environ." Monit.,3: 133-136, 1993

[50] Santhakumar, M. and Balaji, M., "Acute toxicity of an organophosphorus insecticide monocrotophos and its effects on behaviour of an air-breething fish, Anabas testudineus(Bloch)". J. Environ. Biol., 21(2): 121-123, 2000.

[51] Smetak K. M., Johnson-Maynard J. L., Lloyd J. E., "Earthworm population density and diversity in different-aged urban systems," in Appl Soil Ecol., 37:161-8, 2007.

[52] Surendra, K. Y., "Pesticide applications-threat to ecosystems". J. Hum. Ecol., 32(1): 37-45, 2010

[53] Surendra, K. Y., "Pesticide applications-threat to ecosystems". J. Hum. Ecol., 32(1): 37-45, 2010.

[54] Technical Information Sheet, F., Frontline TopSpot, fipronil 9.7\% w/w, MSDS (Athens (GA), Rhone Merieux), 1997.

[55] Tingle, C. C. D., Rother, J. A., Dewhurst, C. F., Lauer, S., King, W. J., "Fipronil: environmental fate, ecotoxicology and human health concerns". Reviews of Environmental Contamination and Toxicology, v. 176, p. 1-66, 2003.

[56] Toccalino, P. L. and Norman, J. E., "Health-based screening levels to evaluate US Geological Survey groundwater quality data". Risk Analysis, 26: 1339-1348, 2006

[57] U. S. E. P. A., "Fipronil; Pesticide Tolerance". Federal Register: July 17, 1998 (Volume 63, Number 137) [OPP-300612; FRL-5768-3] Office of, Pesticides Programs, Washington DC, 1998.

[58] US Environmental Protection Agency, U. E., "New pesticide fact sheet fipronil (Washington, DC, US Environmental Protection Agency Office of Prevention, Pesticide and Toxic Substances)", 1996.

[59] Van Maele-Fabry, G., Lantin, A. C., Hoet, P., Lison, D., "Childhood leukaemia and parental occupational exposure to pesticides: a systematic review and meta-analysis". Cancer Causes Control 21 (6), 787-809, 2010.

[60] Watanab, M., "On amounts of cast production by the megascolecial earthworm Pheretimalupeinsis". Pedobiol 15:20-28, 1975.

[61] Wickerham, E. L., Lozoff, B., Shao, J., Kaciroti, N., Xia, Y., Meeker, J. D., "Reduced birth weight in relation to pesticide mixtures detected in cord blood of full-term infants. Environ". Int. 47, 80-85, 2012. 